\title{
Reply to the letter by Dr. Gurvits
}

\section{Michael Tsokos}

Published online: 26 June 2011

(C) Springer Science+Business Media, LLC 2011

Dr. Gurvit's comment on our paper [1] is interesting. However, in the case presented, exsanguination as the immediate cause of death was proven without any doubt at autopsy by sparse post-mortem lividity and marked pallor of all internal organs, in the presence of two major bleeding sites. Ventricular fibrillation as a cause of death may be a useful "diagnosis" in a clinical setting when the autopsy results are not available. However, forensic pathology has the great advantage of getting deeper insights into clarifying the immediate cause of death by autopsy than any clinician can.

\section{Reference}

1. Tsokos M. Black esophagus. Forensic Sci Med Pathol. 2011; doi: 10.1007/s12024-011-9222-0.

M. Tsokos ( $\square)$

Institute of Legal Medicine and Forensic Sciences, Charité-

Universitätsmedizin Berlin, Turmstr. 21 (Haus N), 10559 Berlin,

Germany

e-mail: mtsokos@web.de 